\title{
Kinetic and Thermodynamic Studies on the Non-Isothermal Decomposition of Lanthanum Oxalate Hydrate, Catalysed By Transition Metal Nano Oxides
}

\author{
H. Nayak* \\ P.G. Department of Chemistry, Orissa University of Agriculture and Technology, Bhubaneswar 751003 \\ E mail : himansu110@gmail.com
}

\begin{abstract}
A study on the thermal decomposition of the mixtures of lanthanum oxalate hydrate and transition metal nano oxide compounds(TMNOCs) viz. $\mathrm{CuO}, \mathrm{Fe}_{2} \mathrm{O}_{3}, \mathrm{TiO}_{2}$ and $\mathrm{Cr}_{2} \mathrm{O}_{3}$ of 5 mole\% ratio has been carried out employing Thermogravimetry, Differential Thermal Analysis and chemical analysis. The results reveal that other than $\mathrm{CuO}$ the oxides have a retarding effect on the decomposition rate. There is a competition of rate between $\mathrm{Fe}_{2} \mathrm{O}_{3}$ and $\mathrm{TiO}_{2}$ mixture up to $696 \mathrm{~K}$ after which the trend is reversed and $\mathrm{Fe}_{2} \mathrm{O}_{3}$ becomes relatively more catalytic than $\mathrm{TiO}_{2}$. The best explanation for catalytic activities of the oxides is made by taking the former as a function of electronic configuration of the metal rather than the electronic properties of the oxides. Abnormal behaviour of $\mathrm{Cr}_{2} \mathrm{O}_{3}$ may be attributed to an irreversible change in oxidation state of $\mathrm{Cr}^{3+}$ during which it is oxidised to $\mathrm{Cr}^{6+}$ prior to decomposition. The kinetic and thermodynamic parameters are evaluated in the light of $F_{3}$ mechanism in two different regions of $\alpha$ 's and the rate follows the order:
\end{abstract}

$S_{1}<S_{2}>S_{3}<S_{4}>S_{5}(0.1<\alpha<0.5)$

$S_{1}<S_{2}>S_{3}>S_{4}>S_{5}(0.5<\alpha<0.9)$

Where $S_{1}, S_{2}, S_{3}, S_{4}$ and $S_{5}$ stand for mixtures of different oxides with lanthanum oxalate.

Keywords: Lanthanum oxalate, transition metal oxide, catalyst effect, TG, electronic configuration, kinetic parameters.

\section{Introduction}

Metal oxides are an important class of chemicals having wide-ranging applications in many areas of chemistry, physics and material science. In technological applications, metal oxides are used in the fabrication of micro-electronic circuits, sensors, fuel cells, and as catalysts Metal oxide nanocrystals can exhibit unique physico-chemical properties and especially Transition metal oxides (TMOs) have received considerable attention in recent years for their catalytic, electronic and magnetic properties. Nano meter sized metal oxides are expected to possess better properties than those of bulk metal oxides[30]. .EI-Awad et al [1-2] have reviewed, the mechanical addition of foreign substances to metal salts results significant changes in the thermochemical behaviour of the material which may arise due to catalytic activity of the additives [3]. It has been generally recognised that for many simple and complex oxalates, endothermic decomposition in nitrogen, becomes exothermic in air which has been explained as arising from catalytic conversion of carbon monoxide to carbon dioxide, with the solid product providing the catalytic surface.

Thermo analytical studies on decomposition of hydrated zinc oxalate [4-7], nickel oxalate [8-11] and iron (11) oxalate $[4,9,12-18]$ are also known to exhibit endothermic decarboxylation steps in oxygen free environment, that change to exothermic ones in air/ oxygen which is explained as arising from secondary oxidation of carbon monoxide catalysed by the metal oxides. According to Shimokawbe et al [19] transition metal oxides $\mathrm{Cr}_{2} \mathrm{O}_{3}, \mathrm{MnO}_{2}$ and $\mathrm{Fe}_{2} \mathrm{O}_{3}$ have highest catalytic activities towards decomposition, due to higher electrical conductivities. It was suggested that, the catalytic activity is related to electron hopping [20, 21]. But according to Feng et al [22] the metal oxides containing metal cations with half filled d-orbitals is likely to have high activities.

The present work deals with the thermal decomposition of lanthanum oxalate hydrate $\mathrm{La}_{2}\left(\mathrm{C}_{2} \mathrm{O}_{4}\right)_{3} \cdot 10 \mathrm{H}_{2} \mathrm{O}$ till $800^{\circ} \mathrm{C}$, in air, is investigated by non-isothermal gravimetry and differential thermal analyses[27,32,33]. Intermediates and final solid products were characterized by X-ray diffraction (XRD) and IR-spectroscopy, the results show that $\mathrm{La}_{2}\left(\mathrm{C}_{2} \mathrm{O}_{4}\right)_{3} \cdot 10 \mathrm{H}_{2} \mathrm{O}$ dehydrates in stepwise at $86-360^{\circ} \mathrm{C}$ and decomposes to $\mathrm{La}_{2} \mathrm{O}_{3}$ at $710^{\circ} \mathrm{C}$ through different intermediates, $\mathrm{La}_{2}\left(\mathrm{C}_{2} \mathrm{O}_{4}\right)_{3}, \mathrm{La}_{2} \mathrm{O}\left(\mathrm{CO}_{3}\right)_{2}$ and $\mathrm{La}_{2} \mathrm{O}_{2} \mathrm{CO}_{3}$, that form at 400,425 and $470{ }^{\circ} \mathrm{C}$, respectively whereas the catalytic effect of transition metal oxides on their decomposition has not drawn much attention. Hence the present work has been carried out and The purpose of this study is to prepare different TMONCs and therefore, in the present communication, preparation of metal oxide nanocrystals (CuO, 
$\mathrm{Cr}_{2} \mathrm{O}_{3}, \mathrm{Fe}_{2} \mathrm{O}_{3}$ and $\mathrm{TiO}_{2}$ ) has been carried out via a novel quick precipitation method[31] The size of the nanocrystals is controlled in this route and, to compare their relative activities towards the thermal decomposition of lanthanum oxalate. The correlation between the catalytic activities and the electron configurations of the metal cations in the oxides will be discussed based on the relative activities.

\section{Preparation of Lanthanum Oxalate}

\section{Experimental Methods}

Lanthanum oxalate was prepared by precipitation from oxalic acid (AR grade) and lanthanum nitrate (Indian rare earth) in a dilute aqueous solution and the crystals were dehydrated in vaccum at $493 \mathrm{~K}$ to a constant weight. Purity (99\%) of the sample was checked by estimating lanthanum and oxalate by chemical analysis.

\section{Preparation of Metal Oxide Nanocrystals}

All of the metal nanocrystals were prepared by a novel quick precipitation method, as reported earlier[31] which involves mixing a corresponding metal $(\mathrm{Cu}, \mathrm{Cr}, \mathrm{Fe}, \mathrm{Ti})$ acetate aqueous solution to glacial acetic acid under reflux condition, followed by additionof $\mathrm{NaOH}$ at $100^{\circ} \mathrm{C}$ until the $\mathrm{pH}$ was $6-7$. After being cooled to room temperature, the precipitate was centrifuged, washed once with distilled water and three times with absolute ethanol,respectively, and dried in air at room temperature

Physical mixtures of the oxalate were prepared with nano oxide crystals $\mathrm{CuO}, \mathrm{Cr}_{2} \mathrm{O}_{3}, \mathrm{Fe}_{2} \mathrm{O}_{3}$ and $\mathrm{TiO}_{2}$ (5.0 mol\% each) by grinding them in an agate mortar. The particles of uniform mesh size of different mixtures were subjected to thermal decomposition using SHEMATZU DTG 50 thermal analyser using alumina crucible and $\alpha$ - alumina as reference, at a heating rate of $4^{0} \mathrm{C} \mathrm{min}^{-1}$, in air.

\section{FTIR Spectral data}

\section{Results \& Discussion}

FTIR spectra of $\mathrm{La}_{2}\left(\mathrm{C}_{2} \mathrm{O}_{4}\right)_{3} \cdot 10 \mathrm{H}_{2} \mathrm{O}$ and the intermediates heated at 140 and $250{ }^{\circ} \mathrm{C}$ are shown in Fig. 1. It can be seen that these three spectra are very similar, demonstrating that only water molecules are lost at the three mass loss stages.

The IR spectra of prepared lanthanum oxalate exhibit three distinct peaks at $1618 \mathrm{~cm}^{-1}(-\mathrm{C}=\mathrm{O}), 1316$ $\mathrm{cm}^{-1}(\mathrm{C}-\mathrm{O})$ and $796 \mathrm{~cm}^{-1}(\mathrm{M}-\mathrm{O})$ suggesting the presence of the oxalate ion. An extra peak at $2348 \mathrm{~cm}^{-1}$ is shown indicating the presence of carbon dioxide. The IR spectra of the product after TG obtained at $490^{\circ} \mathrm{C}$ suggest the incomplete combustion and $86 \%$ of the decomposition takes place as indicated by chemical analysis. Peaks are obtained at 1432,1100, 1000 and $858 \mathrm{~cm}^{-1}$. The appearance of small peak at $1100 \mathrm{~cm}^{-1}$ concurrent with the diminution of oxalate peak suggest a carbonate or carbonate like decomposition intermediate. The prominent peak at $1432 \mathrm{~cm}^{-1}$ is due to carbonate ion. Another peak with a shoulder to it is obtained at a slightly lower energy $\left(1000 \mathrm{~cm}^{-1}\right)$. The fourth stage locates approximately between $372.4{ }^{\circ} \mathrm{C}$ and $600{ }^{\circ} \mathrm{C}$ which could be assigned to the decomposition of $\mathrm{La}_{2}\left(\mathrm{C}_{2} \mathrm{O}_{4}\right)_{3}$ into $\mathrm{La}_{2} \mathrm{O}_{2} \mathrm{CO}_{3}$. A more plausible decomposition scheme is proposed.

$$
\mathrm{La}_{2}\left(\mathrm{C}_{2} \mathrm{O}_{4}\right)_{3} \rightarrow \mathrm{La}_{2} \mathrm{O}\left(\mathrm{CO}_{3}\right)_{2} \rightarrow \mathrm{La}_{2} \mathrm{O}_{2}\left(\mathrm{CO}_{3}\right)+3 \mathrm{CO} \uparrow+2 \mathrm{CO}_{2} \uparrow
$$

which explains the sequence of the IR data. The intermediate band at $1100 \mathrm{~cm}^{-1}$ would be due to the monoxy dicarbonate and peak at $1000 \mathrm{~cm}^{-1}$ is due to dioxy monocarbonate. Formation of species like $\mathrm{CO}_{3}{ }^{2-}, \mathrm{CO}_{2}, \mathrm{CO}$ etc is also confirmed by earlier works.[27]

FTIR spectra of solid phases heated at 500 and $600{ }^{\circ} \mathrm{C}$ are shown in Fig. 1. The broad absorption band peaks at $1501,1450,1357$ and $851 \mathrm{~cm}^{-1}$ are the indication of characteristic absorption peaks of the monoclinic $\mathrm{La}_{2} \mathrm{O}_{2} \mathrm{CO}_{3}[27,35 \AA]$. The fifth stage locates at approximately 600 and $745.6{ }^{\circ} \mathrm{C}$, which account for the conversion of $\mathrm{La}_{2} \mathrm{O}_{2} \mathrm{CO}_{3}$ to $\mathrm{La}_{2} \mathrm{O}_{3}$. The decomposition reaction is as follows:

$$
\mathrm{La}_{2} \mathrm{O}_{2} \mathrm{CO}_{3} \rightarrow \mathrm{La}_{2} \mathrm{O}_{3}+\mathrm{CO}_{2} \uparrow
$$

It can be seen from the FTIR spectra of 700 and $800^{\circ} \mathrm{C}$ that the characteristic absorbance bands at about $649 \mathrm{~cm}^{-1}$ is the $\mathrm{La}-\mathrm{O}$ stretching vibration. The broad absorption band at about $3604 \mathrm{~cm}^{-1}$ corresponding to hydroxyl stretching vibration is present, which may be due to the surface adsorbed water by nascent state $\mathrm{La}_{2} \mathrm{O}_{3}$. 

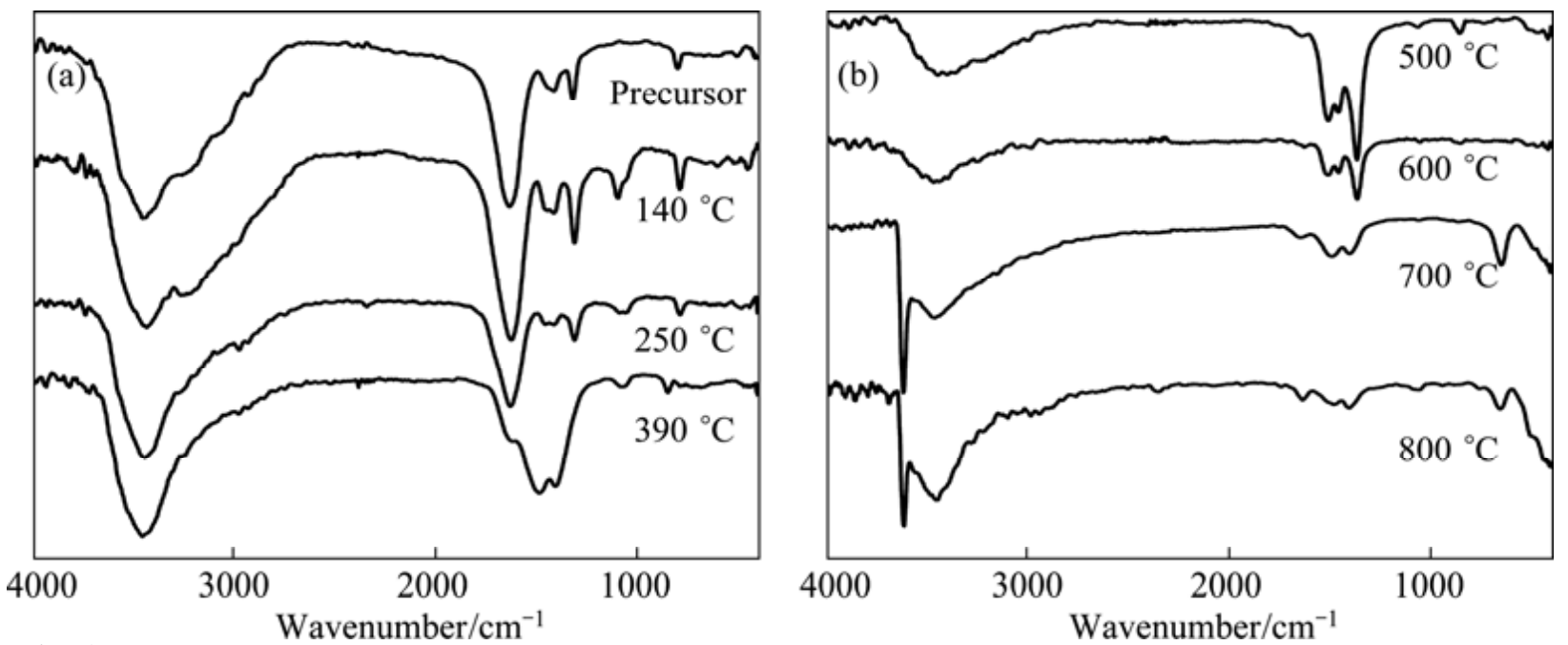

Fig. 1 FTIR spectra of precursor and powders heated at different temperatures: (a) Precursor and intermediate;

(b) Intermediate

XRD analysis of the prepared TMNOCs:

XRD measurements were performed on the TMO nanocrystals by an advanced X-ray diffractometer using $\mathrm{CuK} \alpha$ radiation $(\lambda=1.5418 \AA)$. The diffraction patterns are shown in Fig. 2. Particle size of the crystals was calculated by applying Scherrer's formula to the powder XRD data,The intensity of XRD peaks of the sample reflects that the formed nanoparticles are crystalline and broad diffraction peaks indicate very small size crystallite.

Fig 2. $\mathrm{XRD}$ patterns of $\mathrm{Fe}_{2} \mathrm{O}_{3} \mathrm{Fig}(\mathrm{a}), \mathrm{CuO}, \mathrm{Fig}(\mathrm{b}) \mathrm{TiO}_{2} \mathrm{Fig}(\mathrm{c})$, and $\mathrm{Cr}_{2} \mathrm{O}_{3} \mathrm{Fig}(\mathrm{d})$

Fig(a)

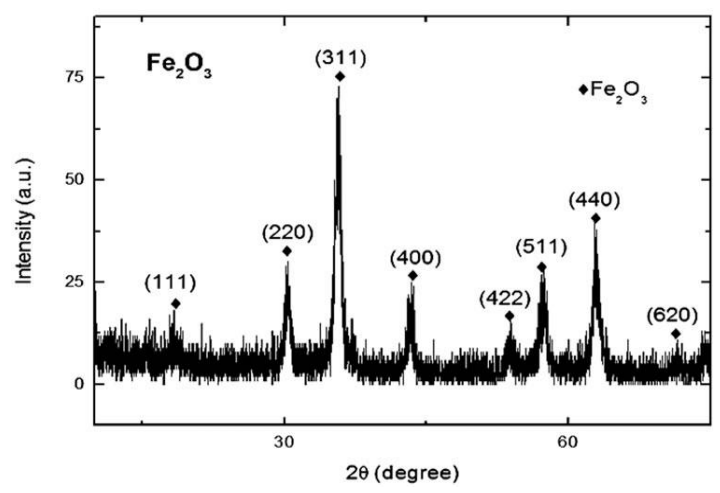

$\operatorname{Fig}(\mathrm{c})$

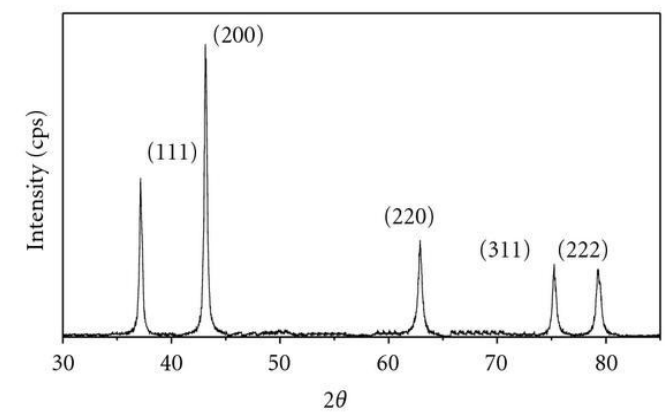

Fig(b)

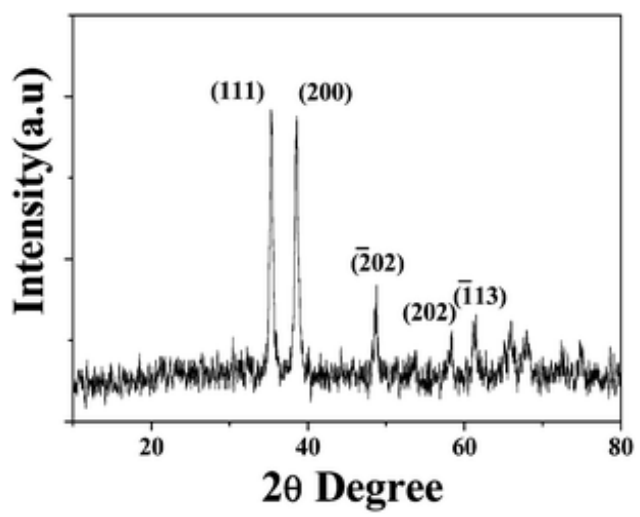

$\operatorname{Fig}(d)$

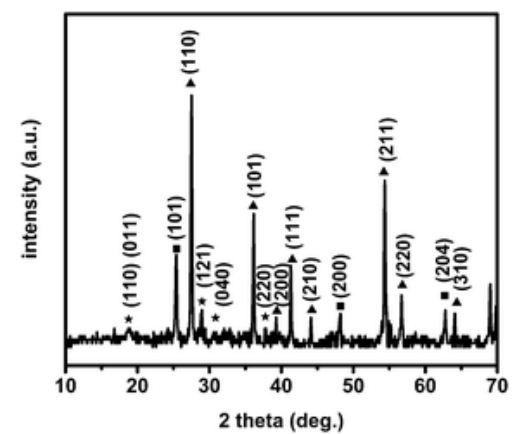

TEM was used to further examine the particle size, crystallinity and morphology of samples.TEM bright field images of $\mathrm{TiO}_{2}, \mathrm{CuO}, \mathrm{Fe}_{2} \mathrm{O}_{3}$ and $\mathrm{Cr}_{2} \mathrm{O}_{3}$ micropowders are shown in Fig. 3. It is clearly seen that the the powders crystalline phase consist of both spherical and rod shapes but the particle of $\mathrm{Fe}_{2} \mathrm{O}_{3}$ powders are mostly spherical morphology. Furthermore, it can be estimated that the particle size of samples are in microscale with the grain size of powders are in nanoscale with the grain size less than $100 \mathrm{~nm}$. 
Fig(a)

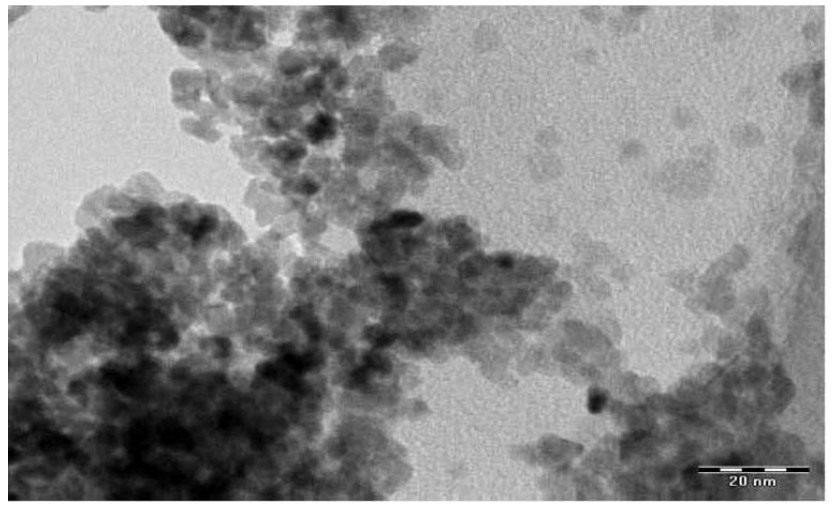

Fig $(c)$

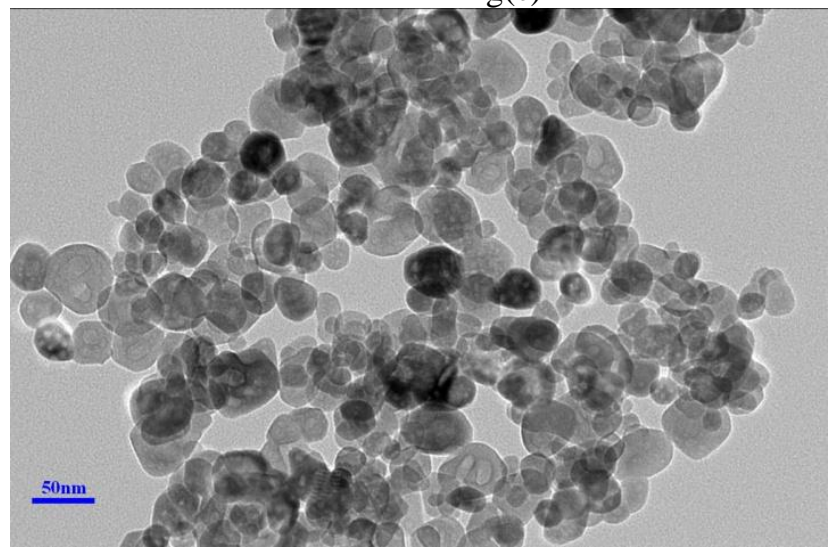

$\operatorname{Fig}(b)$

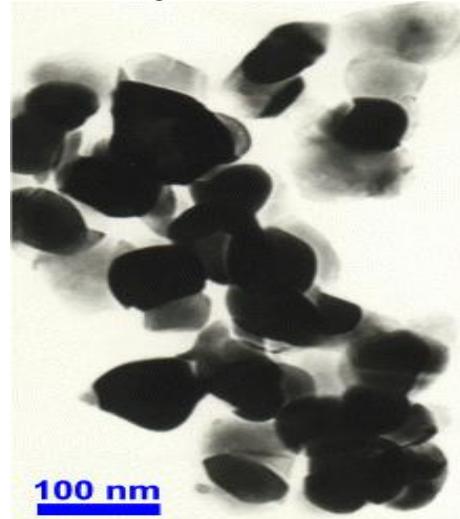

Fig(d)

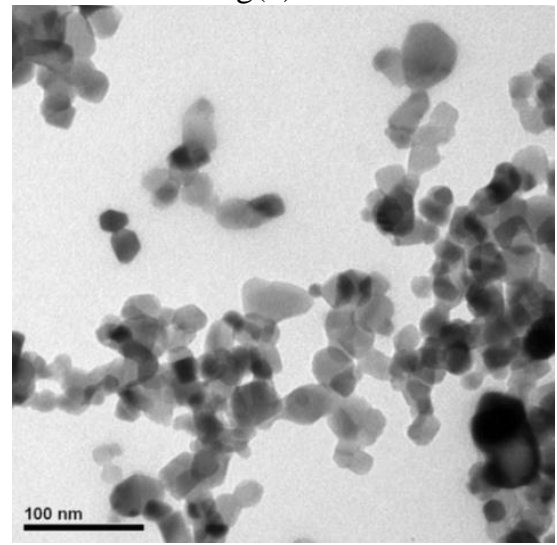

$\mathrm{Cr}_{2} \mathrm{O}_{3} \mathrm{Fig}(\mathrm{c})$ and $\mathrm{TiO}_{2} \mathrm{Fig}(\mathrm{d})$

Thermal analysis TG and DTA of lanthanum oxalate were carried out on heating at rate of $4{ }^{\circ} \mathrm{C} \mathrm{min}^{-1}$ up to $800{ }^{\circ} \mathrm{C}$ in a dynamic atmosphere of air $(20 \mathrm{ml} / \mathrm{min})$, using a thermal analysis model SHEMATZU DTG 50 Analyzer. Ten to fifteen milligrams portions of the test sample were used for the TG measurements, and highly sintered $\alpha-\mathrm{Al}_{2} \mathrm{O}_{3}$ was the thermally inert reference for the DTA. At the first stage, a weak decomposition occurs in the temperature range of $25-226.2{ }^{\circ} \mathrm{C}$ The experimental mass loss $(14.5 \%)$ of the first stage is very close to the theoretical mass loss $(14.9 \%)$, which could be attributed to the evolution of six water molecules. The second stage beginning at about $226.2{ }^{\circ} \mathrm{C}$ and ending at $295.2{ }^{\circ} \mathrm{C}$ with a mass loss about $4.9 \%$ can be assigned to the loss of two water molecules with the increased temperature. The third stage occurs between $295 .{ }^{\circ} \mathrm{C}$ and 372.4 ${ }^{\circ} \mathrm{C}$, with a mass loss about $5.03 \%$, indicating that the last two water molecules of lanthanum oxalate decahydrate are lost. The previous three stages of thermal decomposition process are expressed as follows:

$\mathrm{La}_{2}\left(\mathrm{C}_{2} \mathrm{O}_{4}\right)_{3} \cdot 10 \mathrm{H}_{2} \mathrm{O} \rightarrow \mathrm{La}_{2}\left(\mathrm{C}_{2} \mathrm{O}_{4}\right)_{3} \cdot 4 \mathrm{H}_{2} \mathrm{O}+6 \mathrm{H}_{2} \mathrm{O}$

$\mathrm{La}_{2}\left(\mathrm{C}_{2} \mathrm{O}_{4}\right)_{3} \cdot 4 \mathrm{H}_{2} \mathrm{O} \rightarrow \mathrm{La}_{2}\left(\mathrm{C}_{2} \mathrm{O}_{4}\right)_{3} \cdot 2 \mathrm{H}_{2} \mathrm{O}+2 \mathrm{H}_{2} \mathrm{O}$

$\mathrm{La}_{2}\left(\mathrm{C}_{2} \mathrm{O}_{4}\right)_{3} \cdot 2 \mathrm{H}_{2} \mathrm{O} \rightarrow \mathrm{La}_{2}\left(\mathrm{C}_{2} \mathrm{O}_{4}\right)_{3}+2 \mathrm{H}_{2} \mathrm{O}$

Lanthanum oxalate exhibits two stages of decomposition. The fourth stage occurs approximately between $372.4{ }^{\circ} \mathrm{C}$ and $600{ }^{\circ} \mathrm{C}$ involving fast $(653-683 \mathrm{~K})$ and a slow $(683-793 \mathrm{~K})$ stage. The product formed is $\mathrm{La}_{2} \mathrm{O}_{2}\left(\mathrm{CO}_{3}\right)$, a dioxymonocarbonate
$\mathrm{La}_{2}\left(\mathrm{C}_{2} \mathrm{O}_{4}\right)_{3}$ $\rightarrow \mathrm{La}_{2} \mathrm{O}\left(\mathrm{CO}_{3}\right)_{2}+3 \mathrm{CO}+\mathrm{CO}_{2}$
$\mathrm{La}_{2} \mathrm{O}\left(\mathrm{CO}_{3}\right)_{2}$
$>\mathrm{La}_{2} \mathrm{O}_{2}\left(\mathrm{CO}_{3}\right)+\mathrm{CO}_{2}$

(iv)

During the addition of transition metal oxides, the number of stages remain unaltered rather their positions are changed in TG, e.g. in case of $\mathrm{CuO}$ the fast stage occurs at $653-683 \mathrm{~K}$. But the slow stage at 683 $763 \mathrm{~K}$. In case of $\mathrm{Fe}_{2} \mathrm{O}_{2}$ and $\mathrm{TiO}_{2}$, the corresponding stages occur at $673-703 \mathrm{~K}$ and $703-793 \mathrm{~K}$ respectively. But in case of $\mathrm{Cr}_{2} \mathrm{O}_{3}$ the decomposition temperature undergoes a remarkable shift and the entire decomposition process changes to one step process, occurring at $683-783 \mathrm{~K}$. (Fig. 4 ) 
$\mathrm{CuO}$ has a catalytic effect on the decomposition of lanthanum oxalate, whereas other oxides act as negative catalysts which can also be observed from their corresponding DTG plots (Fig. 5). Analysing the catalytic activites of the additives in term of fractional decomposition $\alpha$, it is found that $50 \%$ decomposition temperature $\left(\mathrm{T}_{0.5}\right)$ are $680 \mathrm{~K}, 699.5 \mathrm{~K}, 700.5 \mathrm{~K}$ and $721 \mathrm{~K}$ for $\mathrm{CuO}, \mathrm{Fe}_{2} \mathrm{O}_{3}, \mathrm{TiO}_{2}$ and $\mathrm{Cr}_{2} \mathrm{O}_{3}$ respectively(Table -1$)$. The shift of decomposition temperatures to higher values can be explained on the basis of increased stability of the oxalate after adding the oxide additives. During heating in a thermal analyser there is a partial displacement of $\mathrm{La}^{3+}$ by metal cations of the oxides viz. $\mathrm{Cu}^{2+}, \mathrm{Fe}^{3+}, \mathrm{Ti}^{4+}$ and $\mathrm{Cr}^{3+}$. The transition metal cations other than $\mathrm{Cr}^{3+}$ have higher charge density that $\mathrm{La}^{3+}$ ion and hence from a stronger $\mathrm{M}-\mathrm{O}$ covalent bond. Hence the stability of $\mathrm{C}-\mathrm{C}$ bond increases thereby increasing the decomposition temperature.

$\mathrm{CuO}$ on the other hand when used as additive slightly decreases the $50 \%$ DT to $680 \mathrm{~K}$ from $685 \mathrm{~K}$ (which is obtained in case of pure lanthanum oxalate). The fact is explained on the basis of electron transfer involved between the $\mathrm{C}_{2} \mathrm{O}_{4}{ }^{2-}$ ion and $\mathrm{CuO}$, before the cleavage of ' $\mathrm{C}-\mathrm{C}^{\prime}$ bond, resulting - stepwise reduction of $\mathrm{Cu}^{2+}$ as [23].

$$
\mathrm{Cu}^{2+}
$$

TABLE- 1

Decomposition regions for various categories of samples determined at a heating rate of $4{ }^{\circ} \mathrm{C} \mathrm{min}-1$.

\begin{tabular}{|l|l|l|l|}
\hline Samples & Stage 1 & Stage II & $T_{\alpha=0.5}$ \\
\hline $\mathrm{LaOX}$, Pure & $663-683 \mathrm{~K}$ & $683-773 \mathrm{~K}$ & $683.2 \mathrm{~K}$ \\
\hline $\mathrm{LaOX}+\mathrm{CuO}$ & $663-683 \mathrm{~K}$ & $683-743 \mathrm{~K}$ & $680 \mathrm{~K}$ \\
\hline $\mathrm{LaOX}+\mathrm{Fe}_{2} \mathrm{O}_{3}$ & $673-703 \mathrm{~K}$ & $703-793 \mathrm{~K}$ & $699.5 \mathrm{~K}$ \\
\hline $\mathrm{LaOX}+\mathrm{TiO}_{2}$ & $673-703 \mathrm{~K}$ & $703-793 \mathrm{~K}$ & $700.5 \mathrm{~K}$ \\
\hline $\mathrm{LaOX}+\mathrm{Cr}_{2} \mathrm{O}_{3}$ & $683-783 \mathrm{~K}$ & $723-793 \mathrm{~K}$ & $721 \mathrm{~K}$ \\
\hline
\end{tabular}

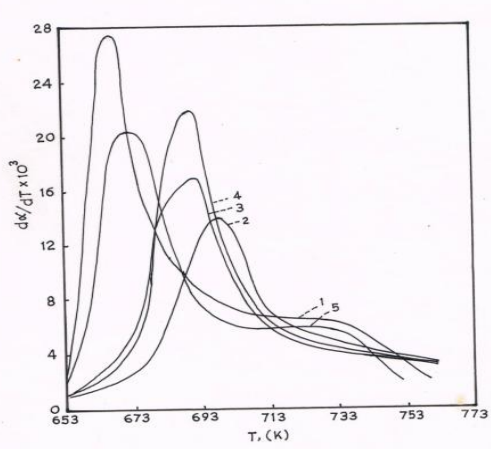

Fig.5 Derivative curves of decomposition of various samples

$\mathrm{LaOX}(1), \mathrm{LaOX}+\mathrm{Cr}_{2} \mathrm{O}_{3}(2), \mathrm{LaOX}+\mathrm{TiO}_{2}(3)$, $\mathrm{LaOX}+\mathrm{Fe}_{2} \mathrm{O}_{3}(4), \mathrm{LaOX}+\mathrm{CuO}(5)$

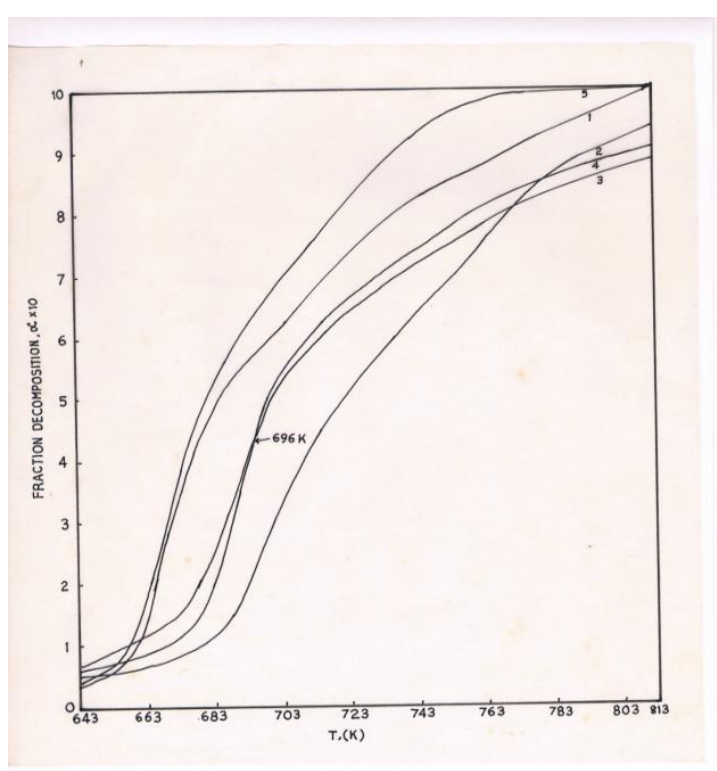

Fig.4 Thermogravimetric curves for the decomposition of Lanthanum Oxalate mixed with various oxides

$\mathrm{LaOX}(1), \mathrm{LaOX}+\mathrm{Cr}_{2} \mathrm{O}_{3}(2), \mathrm{LaOX}+\mathrm{TiO}_{2}$ (3), $\mathrm{LaOX}+\mathrm{Fe}_{2} \mathrm{O}_{3}(4), \mathrm{LaOX}+\mathrm{CuO}(5)$ 


\section{Kinetic Analysis} Redfern eqn.

The thermogravimetric data on all the categories of samples were analysed with the help of Coat -

$$
\log [g(\alpha)] / T^{2}=\operatorname{Iog} A R / \beta E-E / 2.303 R T
$$

where $\mathrm{A}$ is the pre-exponential factor $\beta$, the heating rate, $\mathrm{E}$ the energy of activation, $\mathrm{R}$ the universal gas constant and ' $T$ ' the absolute temperature $\log [g(\alpha)] / T^{2}$ is calculated for each possible rate controlling mechanisms and the best fit one $\mathrm{F}_{3}$ is chosen which gives the unity value of correlation coefficients when the former is plotted against $1 / \mathrm{T}$. The kinetic parameters such as ' $\mathrm{E}$ ' \& ' $\mathrm{A}$ ' are calculated respectively from the slope and intercepts of the plot. (fig. 6) The entire decomposition curve is divided into two regions $(\alpha=0.1-0.5$ and $\alpha=0.5-0.9$ ) and th parameters within those regions. It is found that $\mathrm{CuO}$ has got maximum catalytic effect whereas other metal oxides decatalyse the decomposition process (Table -2). The rate constant ' $k$ ' is calculated for the two separate regions at two different temperatures and followed the order:

Pure $<\mathrm{CuO}>\mathrm{Fe}_{2} \mathrm{O}_{3}<\mathrm{TiO}_{2}>\mathrm{Cr}_{2} \mathrm{O}_{3}(\alpha=0.1$ to 0.5$)$

and $\quad$ Pure $<\mathrm{CuO}>\mathrm{Fe}_{2} \mathrm{O}_{3}>\mathrm{TiO}_{2}>\mathrm{Cr}_{2} \mathrm{O}_{3}(\alpha=0.5$ to 0.9$)$

$\underline{\text { TABLE }-2}$

Fractional decomposition a for various categories of samples obtained during a dynamic termperature decomposition, at a heating rate of $4^{\circ} \mathrm{C} \mathrm{min}^{-1}$

\begin{tabular}{|c|c|c|c|c|c|}
\hline Temperature T,K & \multicolumn{5}{|c|}{ Fractional decomposition, $\alpha$} \\
\hline \multirow{7}{*}{$\begin{array}{l}653 \\
683 \\
713 \\
743 \\
773 \\
793\end{array}$} & $\mathrm{~S} 1$ & $\mathrm{~S} 2$ & S3 & S4 & S5 \\
\hline & 0.0492 & 0.061 & 0.068 & 0.089 & 0.054 \\
\hline & 0.488 & 0.537 & 0.212 & 0.258 & 0.119 \\
\hline & 0.674 & 0.757 & 0.61 & 0.593 & 0.44 \\
\hline & 0.824 & 0.934 & 0.743 & 0.719 & 0.636 \\
\hline & 0.913 & 0.988 & 0.835 & 0.811 & 0.815 \\
\hline & 0.954 & 0.996 & 0.876 & 0.854 & 0.891 \\
\hline
\end{tabular}

$\mathrm{S} 1(\mathrm{Pure} \mathrm{LaOX}), \mathrm{S} 2(\mathrm{LaOX}+\mathrm{CuO}), \mathrm{S} 3\left(\mathrm{LaOX}+\mathrm{Fe}_{2} \mathrm{O}_{3}\right), \mathrm{S} 4\left(\mathrm{LaOX}+\mathrm{TiO}_{2}\right), \mathrm{S} 5\left(\mathrm{LaOX}+\mathrm{Cr}_{2} \mathrm{O}_{3}\right)$

The kinetic along with thermodynamic parameters are presented in Table - 3. It is seen that the entropy change of activation ' $\Delta \mathrm{S}$ ' is positive only in case of $\mathrm{CuO}$ for stage II and in rest of the cases it is found to be ve. Since the decomposition is a unimolecular reaction the -ve value of entropy change indicates an ordered activated complex and slower than normal reaction.

TABLE-3

Determination of Arrhenius and thermodynamic parameters for the decomposition of various samples using $\mathrm{F}_{3}$ mechanism

\begin{tabular}{|c|c|c|c|c|c|c|c|c|c|c|c|c|}
\hline \multirow[t]{2}{*}{ Sample } & \multicolumn{2}{|c|}{$\mathrm{E}, \mathrm{Kj} \mathrm{mole}{ }^{-1}$} & \multicolumn{2}{|c|}{$\log ($ Axs $)$} & \multicolumn{2}{|l|}{$\mathrm{k}, \mathrm{s}^{-1}$} & \multicolumn{2}{|c|}{$\begin{array}{l}-\Delta \mathrm{H}^{*}, \mathrm{Kj} \\
\mathrm{mole}^{-1}\end{array}$} & \multicolumn{2}{|c|}{$\Delta \mathrm{S}^{*}$,e.u } & \multicolumn{2}{|c|}{$-\Delta \mathrm{G}^{*}, \mathrm{Kj} \mathrm{mole}^{-1}$} \\
\hline & $\mathbf{I}^{\mathbf{a}}$ & II $^{\mathbf{b}}$ & $\mathbf{I}^{\mathbf{a}}$ & II $^{\mathbf{b}}$ & $\mathbf{I}^{\mathrm{a}}$ & II $^{\mathbf{b}}$ & $\mathbf{I}^{\mathbf{a}}$ & II $^{\mathbf{b}}$ & $\mathbf{I}^{\mathbf{a}}$ & II $^{\mathbf{b}}$ & $\mathbf{I}^{\mathbf{a}}$ & II $^{\mathbf{b}}$ \\
\hline S1 & 153.98 & 153.97 & 13.3 & 13.22 & 33.54 & 177.6 & 148.3 & 143.88 & 39.58 & 41.7 & 175.34 & 178.45 \\
\hline S2 & 176.15 & 248.67 & 15.13 & 20.69 & 45.74 & 37.49 & 170.47 & 242.57 & -4.55 & 101.3 & 173.58 & 168.34 \\
\hline S3 & 159.4 & 124.15 & 13.4 & 10.73 & 16.26 & 76.59 & 172.1 & 118.05 & -9.72 & 89.4 & 178.74 & 183.35 \\
\hline S4 & 153.66 & 109.25 & 12.98 & 9.55 & 17.0 & 58.35 & 153.91 & 103.15 & -36.52 & 111.96 & 178.86 & 185.42 \\
\hline S5 & 115.74 & 203.08 & 9.77 & 16.2 & 8.312 & 53.74 & 110.1 & 196.99 & -107.16 & 15.34 & 183.29 & 185.74 \\
\hline
\end{tabular}

$\mathrm{a} \rightarrow$ at $683 \mathrm{~K}$

$\mathrm{b} \rightarrow$ at $733 \mathrm{~K}$ 

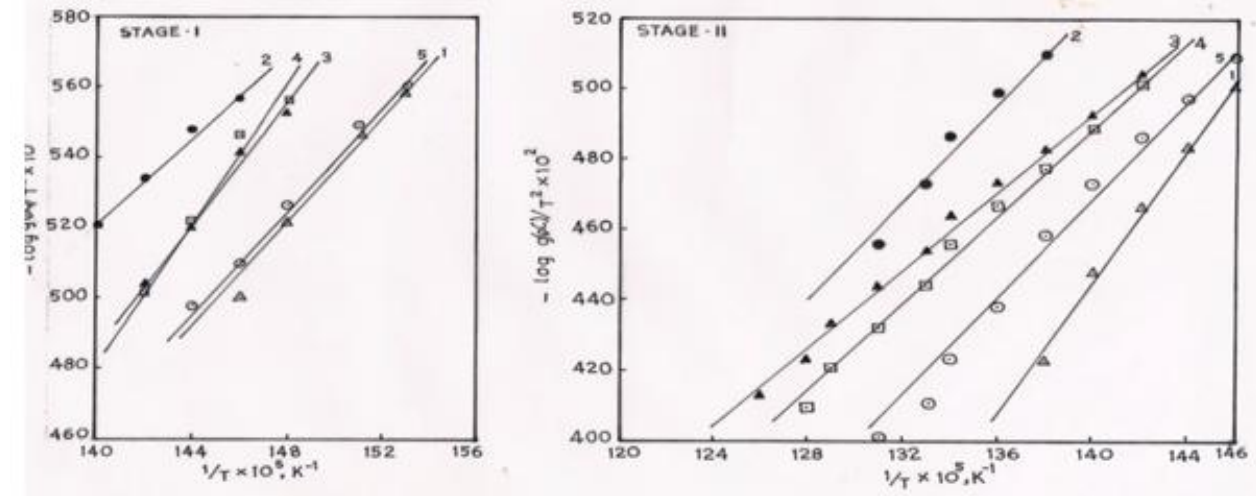

Fig.6 PTots of $-\log g(\alpha) / T^{2}$ vs $1 / \mathrm{T}$ for various samples using $\mathrm{F}_{3}$ mechanism for two different stages of reaction

\section{ROLE PLAYED BY THE OXIDES}

The data on all categories of sample containing $5 \mathrm{~mol} \%$ of oxides suggests that admixuture enhances the role of reaction in case of $\mathrm{CuO}$ in the experimental condition and the rate follows the order:

$$
\mathrm{CuO}>\mathrm{TiO}_{2}>\mathrm{Fe}_{2} \mathrm{O}_{3}>\mathrm{Cr}_{2} \mathrm{O}_{3}
$$

The catalytic activity of metal oxide is determined by the electron configuration of the metal rather than the electronic properties of the oxides. The catalytic process is a process of forming a surface complex between metal cation and oxalate anion. The metal cation on the surface of the oxide are eletrically unsaturated and tend to attract extra electrons or negative charges. The oxygen atom in oxalate anion have unshared electron pairs and can donate one or more of that to the metal cation and act as ligand. This interaction weakens the oxygen carbon bond in $\mathrm{C}_{2} \mathrm{O}_{4}{ }^{2-}$ thus facilitates the decomposition process.

The ability of a metal cation to form co-ordinate bonds depends on its electron configuration. Therefore, the catalytic activity of a metal oxide is determined by the electron configuration if its cation [24].The metal cation of the highly active $\mathrm{CuO}$ have partially filled d-orbital and hence have unfilled valence orbitals. The cation is relatively small in size because there is less electrical shielding. Therefore it has higher tendency to attract extra electrons and and to form surface co-ordination bonds with oxygen atom in $\mathrm{C}_{2} \mathrm{O}_{4}{ }^{2-}$ \& thus has highest activity.

$\mathrm{TiO}_{2}$ containing transition metal cation $\mathrm{Ti}^{4+}$ with $\mathrm{d}^{\mathrm{O}}$ configuration is spherical and the positive electric fields are effectively shielded by electrons. But they have empty d-orbitals to accommodate the electrons from oxalate ion, and can facilitate the formation of the coordination bond, but the activity there is comparatively less than $\mathrm{CuO}$. The $\mathrm{Fe}_{2} \mathrm{O}_{3} \& \mathrm{Cr}_{2} \mathrm{O}_{3}$ oxides although contain metal cations with partially filled d-orbitals, their activities are lower than the other oxides which is probably related to the unique electronic configuration of $\mathrm{Fe}^{3+}$ ion. The $\mathrm{Fe}^{3+}$ has five d-electrons and is in high spin state with spherical symmetry. The electron pair if attracts will have to go to the outer orbital with higher energy levels which is less favoured. Although $\mathrm{Fe}_{2} \mathrm{O}_{3}$ is a moderately active catalyst it is found that the rate is even less than the uncatalysed decomposition of lanthanum oxalate, which may be due to the auto catalytic reactions arising out of formation if $\mathrm{La}_{2} \mathrm{O}_{3}$ type of products and $\mathrm{La}^{3+}$ having $\mathrm{d}^{\mathrm{O}}$ configuration is more active oxide catalyst than than $\mathrm{Fe}_{2} \mathrm{O}_{3}$.

The mechanism of catalyzed lanthanum oxalate thermal decomposition can be understood by the electron-transfer process. The present TG data are recorded below $650{ }^{\circ} \mathrm{C}$, and it is known that lanthanum oxalate thermal decomposition takes place by the electron transfer process in this temperature range. It is possible that metal oxide enhances the decomposition of lanthanum oxalate, on account of their increased electron hole density as has been suggested by earlier works[34]. The presence of a partially filled 3d-orbital may provide help in the electron-transfer process. A positive hole in oxide can accept an electron from oxalate.

The Iow activity of $\mathrm{Fe}_{2} \mathrm{O}_{3}$ is also plausibly explained consistent with the following notaion of semiconductivity [25].

$$
\mathrm{Fe}_{2} \mathrm{O}_{3} \text { (surface) } \square \quad 3 / 2 \mathrm{O}_{2}(\mathrm{~g})+6 \mathrm{e}_{\mathrm{cb}}+2 \mathrm{Fe}^{3+} \mathrm{o}
$$

When the number of electrons in the conduction bond of the oxide is increased due to oxygen loss from 
the surface, initial ' $\mathrm{Fe}^{\mathbf{3 +}} \mathbf{0}$ ' ions are formed. But in air the reverse reaction takes place. The number of $\mathrm{e}^{-}$in the conduction band is decreased leading to lower electrical conductance of the oxides \& hence lower activity, since the activity is a function of overall electrical conductivity [25]. But at high temperature forward reaction is favoured and its activity becomes even more than $\mathrm{TiO}_{2}$.

Moderately active $\mathrm{Cr}_{2} \mathrm{O}_{3}$ although supposed to have higher activity than $\mathrm{Fe}_{2} \mathrm{O}_{3}$ and $\mathrm{TiO}_{2}$ the abnormal behaviour results from an irreversible change in oxidation states of the metal during which its is oxidised to chromate $[23,26]$ during the process prior to the decomposition of oxalate which is inferred from the XRD of the sample taken after TG which do not show any peak for $\mathrm{Cr}_{2} \mathrm{O}_{3}$.

$$
\mathrm{Cr}_{2} \mathrm{O}_{3}
$$

There is no considerable difference in catalytic behaviour of $\mathrm{TiO}_{2}$ and $\mathrm{Fe}_{2} \mathrm{O}_{3}$ since the ion $\mathrm{Fe}^{3+}$ contain $\mathrm{d}^{5}$ configuration and is spherically symmetric analogous to $\mathrm{Ti}^{4+}$. The $\mathrm{TiO}_{2}$ shows good catalytic activity than $\mathrm{Fe}_{2} \mathrm{O}_{3}$ at Iow temperature though both of them are $\mathrm{n}$-type semiconductors due to small ionic radii of $\mathrm{Ti}^{4+}$ \& hence more tendency for surface bond formation with $\mathrm{C}_{2} \mathrm{O}_{4}{ }^{2-}$ ion

\section{Kinetic Compensation Effect}

The kinetic compensation effect for different categories of samples is established within the group of related heterogeneous catalyses for each regions of the reaction. Compensation plots (fig. 7) are obtained for the set of related rate process. Data on compensation parameters $\beta \&$ e together with the correlation coefficient of linear regression analysis has been given in Table 4, using isokinetic relation [28]

$$
\operatorname{In} \mathrm{A}=\beta+\mathrm{eE}
$$
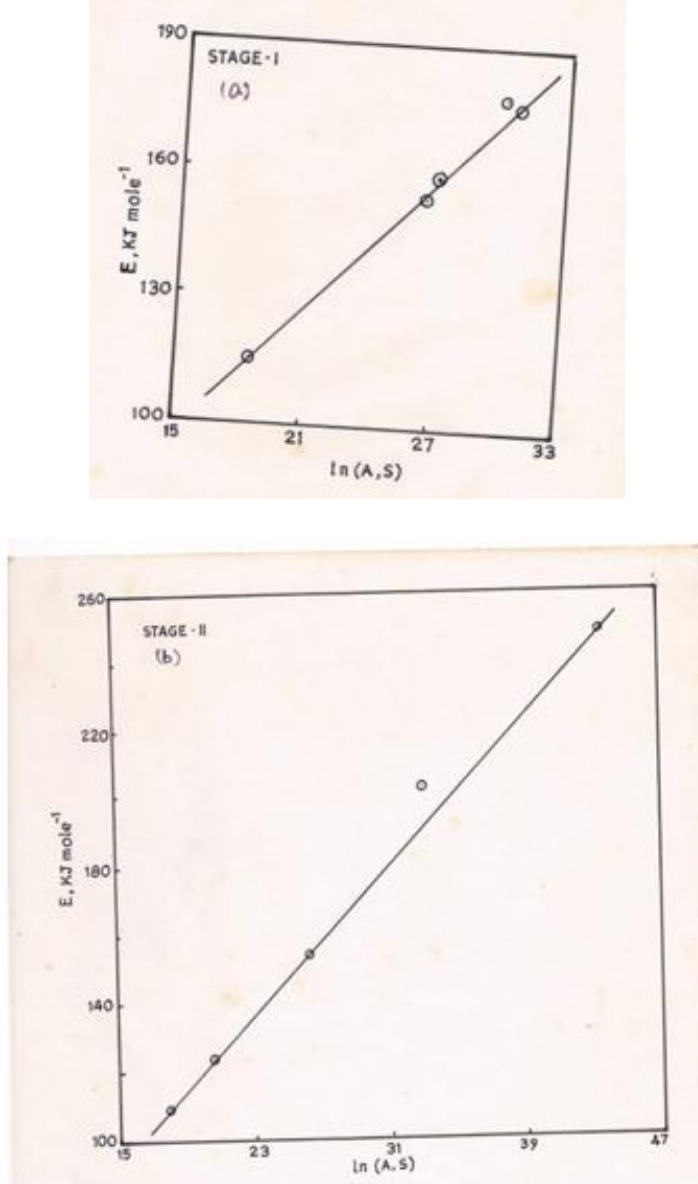

Fig.7 Compensation plots $\ln \mathrm{A}$ vs $\mathrm{E}$ for the samples at the two different stages of reaction

Compensation law is applicable because all the decomposition of the set proceed in very similar temperature interval and is ascribed to the kinetic consistency of the rate processes, which involve rupture of bonds of similar strength in comparable reactants and measured within similar temperature interval [29] 
TABLE-4

Compensation parameters using F3 mechanism in Coat-Redfern equation for each regions in different samples.

\begin{tabular}{|l|lc|l|}
\hline \multirow{2}{*}{ Regions } & \multicolumn{2}{|c|}{ Compensation parameters } & \multirow{2}{*}{ Correlation coefficient } \\
\cline { 2 - 3 } & $\mathrm{e}$ & $-\beta$ & \\
\hline$\alpha=0.1-0.5$ & 0.1954 & 4.0712 & 0.9919 \\
\hline$\alpha=0.5-0.9$ & 0.1786 & 1.6628 & 0.9933 \\
\hline
\end{tabular}

\section{Conclusion}

TMONC were prepared by a novel quick precipitation method (kinetic method) and characterized by XRD and TEM techniques. Their catalytic activity on thermal decomposition of lanthanum oxalate was studied, and they have been found to be good catalysts, as compared to their corresponding normal oxides. The order of the catalytic effect of TMONC in the thermal decomposition of lanthanum oxalate is:

$$
\mathrm{CuO}>\mathrm{TiO}_{2}>\mathrm{Fe}_{2} \mathrm{O}_{3}>\mathrm{Cr}_{2} \mathrm{O}_{3} \text {. }
$$

The mechanism of catalyzed lanthanum oxalate thermal decomposition can be understood by the electron-transfer process. The presence of a partially filled 3d-orbital may provide help in the electron-transfer process. The kinetic compensation effect for different categories of samples is established within the group of related heterogeneous catalyses for each regions of the reaction indicating the accuracy of the model function chosen for the determination of kinetic parameters.

\section{References}

[1] A.M. El - Awad, A. A., Said \& K.M. Abd. EI-Salam; Thermochim. Acta 126 (1988) 17.

[2]. A.M. El - Awad \& R.M. Mohfouz; J.Therm anal 35 (1989) 1413.

[3]. R.M. Gaber, A.M. EI-Awad \& M. M. Giris: J. Therm. Anal 37 (1991 ) 24

[4]. D. Dollimore, D. L. Griffiths; J. Therm, Anal 2 (1970) 229

[5]. B.D. Dalvi, A. M. Chavan, J. Therm. Anal 14 (1978) 331

[6]. Z. Gabelica, R. Hubin, E.G. Derouane, Thermochim Acta 24 (1978) 315

[7]. D. Dollimore; J. Therm. Anal 11 (1977) 187.

[8]. D. Broad bent, D. Dollimore, J. Dollimore; J. Chem Soc A (1966) 278.

[9]. E.D. Macklen; J. Inorg. Nucl. Chem 30 (1968) 2689.

[10]. N. Deb, P. K. Gogoi, N. N. Das, J. Therm. Anal 36 (1990) 465.

[11]. A. Coetzee, D. J. Eve, M. E. Brown; J. Therm Anal 39(1993) 947.

[12]. Y. A Ugai, Zh. Obsh. Chim 24(1954), 1315; Chem. Abstr 49 (1955) 4383 i.

[13]. R.A. Brown, S. C. Beevan :J. Inorg. Nucl Chem 28 (1966) 387.

[14]. D. Dolimore, D. Nicholson; J. Chem. Soc (1962) 960

[15]. D. Dollimore, D. Greffith, D. Nicholson: J. Chem. Soc (1963) 2617.

[16]. D. Broadbent, D. Dollimore, J Dollimore; J. Chem Soc A (1967) 451

[17]. B. Viswanathan, J. Gopalkrishnan, V. Srinivasan, J. Therm Anal 3 (1971 ) 429.

[18]. K.S. Rane, A. K. Nikumbh, A. J. Mukhedkar; J. Mater, Sci. 16 (1981) 2387.

[19]. M. Shimokawabe, R. Furuichi and T. Ishii;Thermochim. Acta 20 (1977) 347.

[20]. A.A. Said, E. A. Hassan, K.M. Abd. El - Salam; Surf Technol. 20 (2) (1983) 131

[21]. H. Iwakura, N. Kakuta, A. Ueno, K. Kishi and J. Kato; Ind. Eng. Chem. Res 30 (1991) 778.

[22]. Z. Feng, Y. Pan, Y. Wu, J. Zhao; Huaxue Tongbao 9 (1988) 43.

[23]. N. Routra, D. Bhatta; J. Therm, Anal 51 (1998) 585.

[24]. Y. Zhang, G. Kshirsagar, J. E. Ellison, J. C. Cannon; Thermochim, Acta 278 (1996) 119

[25]. W.K. Rudloff, E S. Freeman; J. Therm. Anal 18 (1980) 359.

[26]. D. Bhatta, M. K. Sahoo \& S. Misra; Thermochim, Acta 180 (1991) 155.

[27]. H. Nayak, S. K. Pati \& D. Bhatta, Radiat, Eff. \& Def. Solids February 2004, Vol.159,pp.93-106.

[28]. A.K. Galwey; Thermochim. Acta 294 (1997) 205.

[29]. H. Nayak, D. Bhatta, Thermochim, Acta 389 (2002) 109

[30]. G.Singh, I.P.S.Kapoor, S.Dubey and P. F.Siril, J. Sci. Conf. Proceedings Vol. 1, 7-14, 2008

[31]. J. Zhu, D. Li, H. Chen, X. Yang, L. Lu, and X. Wang, Mater. Lett. 58, 3324, (2004).

[32]. Basma A.A. Balboula, A.M. El-Roudia, E.Samira, A.G.Othman; Thermochim. Acta 387 (2002) 109-114

[33]. ZHAN G., YU Jun-xia, XU Zhi-gao, ZHOU Fang, CHI Ru-an; Trans. Nonferrous Met. Soc. China 22(2012) 925-934

[34]. J. Zhu, W. Zhang, H. Wang, et al. J. Inorg. Chem. 20, 863 (2004). 